\title{
EFICIÊNCIA DO PROCESSO DE RECOBRIMENTO DE SEMENTES DE BRÓCOLOS RECOBERTAS COM POLÍMERO EM LEITO DE JORRO
}

\author{
CELINA DE ALMEIDA ${ }^{2}$, SANDRA C. S. ROCHA ${ }^{1}$
}

RESUMO: Neste trabalho, sementes de brócolos foram recobertas em leito de jorro conecilíndrico, com suspensão aquosa de hidroxietilcelulose, visando a aprimorar a técnica do recobrimento de sementes, utilizando o processo fluidodinâmico. Foram investigados os efeitos das variáveis operacionais temperatura do ar de jorro, pressão de ar de atomização e vazão de suspensão de recobrimento, na eficiência do processo e na germinação das sementes. Os resultados revelaram que houve influência das variáveis operacionais na eficiência do processo e na germinação. Verificou-se, também, que as sementes recobertas apresentaram de 2 a $10 \%$ de umidade a menos que as sementes não-recobertas, quando em ambiente com temperatura controlada e saturado de vapor de água em determinado período.

PALAVRAS-CHAVE: germinação, hidroxietilcelulose, Brassica oleracea.

\section{COATING PROCESS EFFICIENCY FOR POLYMER COATED BROCCOLI SEEDS IN SPOUTED BED}

\begin{abstract}
Broccoli seeds were coated in a conical-cylindrical spouted bed with an aqueous suspension of hydroxy ethyl cellulose aiming to improve the seeds coating technique using a fluiddynamic process. An experimental design was applied to investigate the effects of the operating variables: gas temperature, atomizing air pressure and suspension flow rate on the germination of the seeds and on the process efficiency. Results indicated that the operating variables affect both the coating process efficiency and the germination ability. However, the analysis didn't identify differences between the germination potential of coated and uncoated seeds. Coated seeds absorbed up to 10 percent less moisture than the uncoated ones, when the environment temperature and humidity were controlled over a period of time.
\end{abstract}

KEYWORDS: germination, hydroxy ethyl cellulose, Brassica oleracea.

\section{INTRODUÇÃO}

A obtenção de sementes homogêneas e de alta qualidade é o objetivo dos produtores de hortaliças e de forrageiras. Essas espécies geralmente apresentam dificuldade na semeadura direta, devido a sua forma, tamanho, peso, uniformidade na germinação, presença de reguladores de crescimento e dormência, entre outras causas.

Uma das alternativas que se apresenta como solução de várias dessas questões é o uso do recobrimento de sementes com materiais que facilitem a obtenção de um conjunto de características que, em condições naturais, não seriam alcançadas (SAMPAIO \& SAMPAIO, 1994).

O recobrimento de sementes, de modo geral, inclui todo o processo de adição de material, aplicado na superfície das sementes. O termo "semente recoberta" tem sido definido como semente peletizada, encapada ou coberta por filme adesivo. Tais processos podem ser apropriados para cerca de $90 \%$ das espécies de sementes pequenas. Deve ser feita uma seleção das espécies de sementes utilizadas em recobrimento, por meio da avaliação dos custos com o processo e dos benefícios gerados para as sementes (TAYLOR \& HARMAN, 1990).

\footnotetext{
${ }^{1}$ Eng ${ }^{\mathrm{a}}$ Química, Departamento de Termofluidodinâmica, Faculdade de Engenharia Química, UNICAMP, Fone: (0XX19) 3521.3929, Campinas-SP,rocha@unicamp.br

${ }^{2}$ Eng $^{\mathrm{a}}$ Agrônoma, Dra. em Engenharia Química, Pesquisadora Colaboradora, Faculdade de Engenharia Agrícola, UNICAMP, Campinas - SP.

Recebido pelo Conselho Editorial em: 15-12-2006

Aprovado pelo Conselho Editorial em: 25-2-2008
} 
As condições ambientais e o tipo de material de embalagem utilizado para proteger as sementes têm grande importância para a sua conservação fisiológica (LOPES FILHO et al., 1986). Estudos realizados por VALDES \& BRADFORD (1987), sobre o recobrimento e a manutenção da viabilidade de sementes de alface armazenadas, mostram que as sementes analisadas depois de 5 meses de conservação, a $5{ }^{\circ} \mathrm{C}$, germinaram bem, inclusive a $37^{\circ} \mathrm{C}$, independentemente do tipo de recobrimento que as envolvia.

WEST et al. (1985) recobriram sementes de soja com vários tipos de polímeros e observaram a influência do recobrimento em situação de alta concentração de vapor de água em meio ambiente. A proteção foi confirmada para o recobrimento das sementes com cloreto de polivinilidina durante a estocagem. Após 24 horas de exposição das sementes em condições de saturação, a umidade das sementes recobertas com cloreto de polivinilidina aumentou somente $9 \%$, enquanto nas sementes não-recobertas, o aumento de umidade foi acima de $17 \%$.

O recobrimento tipo filme é caracterizado pela formação de uma película que atribui pequeno aumento de massa à partícula, entre 1 e $10 \%$, e praticamente não modifica a sua forma e seu tamanho. As principais vantagens do recobrimento por filme são a utilização de um solvente líquido, a pequena variação de massa e forma das partículas, a versatilidade na formulação do recobrimento e a boa resistência da película protetora (ATAIDE, 1996).

A necessidade de equipamento para o recobrimento em nível industrial foi verificada por LYNE \& JOHNSTON (1981), quando trabalharam com grande quantidade de sementes a serem recobertas. Foi estudada a possibilidade de adaptar um leito de jorro para o processo de recobrimento de sementes. As vantagens de um leito de jorro sobre um tambor de recobrimento para sementes, segundo LIU \& LITSTER (1991), são: não-formação de aglomerados de sementes; as sementes podem ser simultaneamente cobertas e secas; a cobertura obtida é uniforme; é mecanicamente simples.

No trabalho de LIU \& LITSTER (1991), foi utilizado leito de jorro para o recobrimento de 13 diferentes tipos de sementes com fertilizantes, utilizando-se do fosfato monocálcio (MCP) e do fosfato tricálcio (TCP) em liga de metilcelulose. Verificaram que a taxa de recobrimento foi maior para alta umidade relativa do ar, alta viscosidade da suspensão e mostrou-se independente da altura do leito. Obtiveram recobrimento homogêneo com alta eficiência nas condições de menor temperatura, alta taxa de alimentação da suspensão e alta umidade do ar de saída.

O objetivo do presente trabalho foi analisar a eficiência do processo de recobrimento de sementes de brócolos, com suspensão aquosa de hidroxietilcelulose, em leito de jorro, e avaliar os efeitos do processo de recobrimento na germinação das sementes, bem como no controle da umidificação na presença de vapor de água.

\section{MATERIAL E MÉTODOS}

\section{Sistema experimental}

O leito cone-cilíndrico utilizado no processo de recobrimento foi construído em acrílico transparente, para possibilitar a visualização dos fenômenos. As dimensões do leito foram projetadas de acordo com as propriedades físicas da partícula e recomendações da literatura, obtendo-se $\mathrm{D}_{\mathrm{c}}=0,2 \mathrm{~m} ; \alpha=60^{\circ} ; \mathrm{D}_{\mathrm{i}}=0,05 \mathrm{~m} ; \mathrm{H}=0,3 \mathrm{~m} ; \mathrm{H}_{\mathrm{c}}=0,12 \mathrm{~m}$; sendo $\mathrm{D}_{\mathrm{c}}$ - diâmetro interno do leito; $\alpha$ - inclinação da base; Di - diâmetro de entrada do fluido; $\mathrm{H}_{\mathrm{c}}$ - altura do cone, e $\mathrm{H}$ - altura da parte cilíndrica.

O bico atomizador, do tipo duplo fluido, foi instalado na parte superior do leito. A alimentação do atomizador foi feita por linha de ar comprimido e pelo bombeamento da suspensão de recobrimento. O equipamento utilizado é apresentado na Figura 1. 


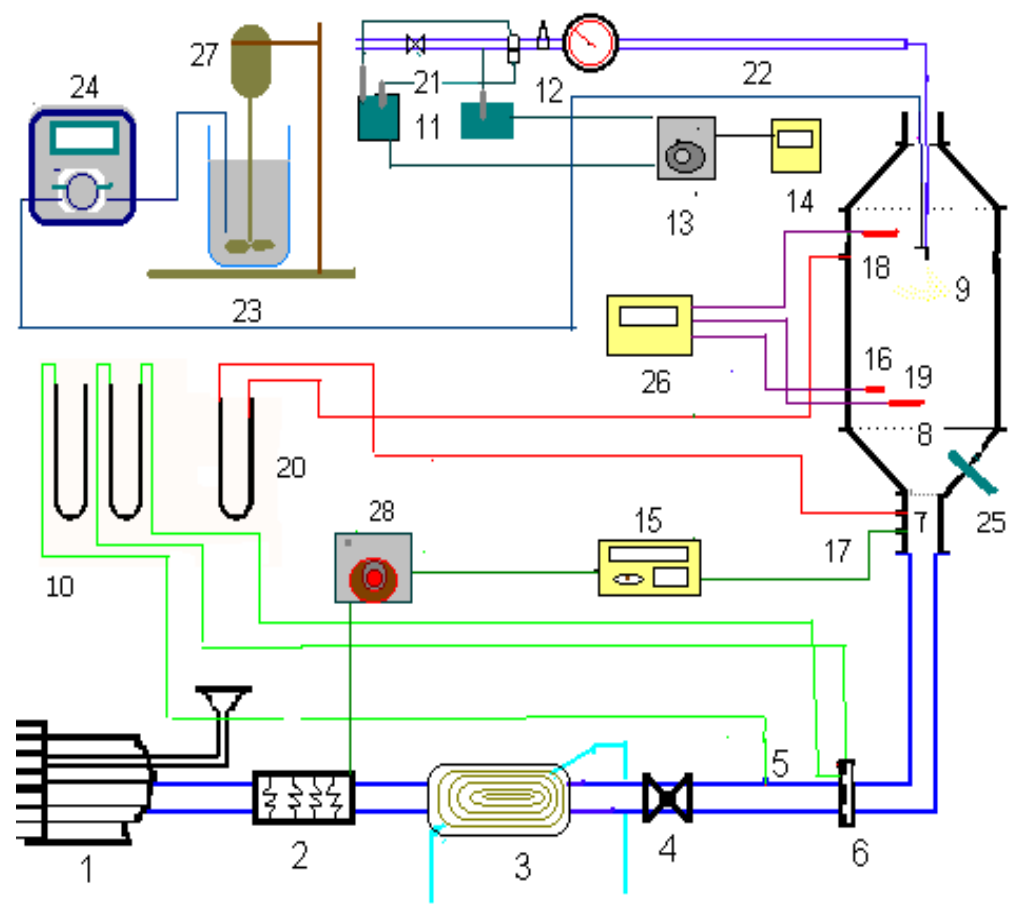

\begin{tabular}{|l|}
\hline Legenda: \\
1 - soprador \\
2 - resistências \\
3 - resfriador de ar \\
4 - válvula para ar do leito \\
5 - tomada de pressão estática \\
6 - placa de orifício \\
7 - instalação da parte cônica do leito \\
8 - instalação da parte cilíndrica \\
9 - bico atomizador \\
10 - manômetros em U \\
11 - transdutores de pressão \\
12 - tomadas de pressão (ar de atomização) \\
13 - seletor de canais para os transdutores \\
14 - indicador da pressão do ar comprimido \\
15 - indicador e controlador de temperatura \\
16 - termopar na região interna (parede) \\
17 - termopar na entrada do leito \\
18 - termopar na saída do leito \\
19 - termopar na região interna central \\
20 - manômetros em U (leito) \\
21 - válvula do ar comprimido \\
22 - tubulação do ar comprimido \\
23 - recipiente com a suspensão \\
24 - bomba peristáltica \\
25 - ponto de retirada das amostras \\
26 - indicador de temperatura \\
27 - agitador \\
28 - variador de voltagem \\
\end{tabular}

FIGURA 1. Esquema do sistema experimental. Experimental setup.

A metodologia da operação para o leito de jorro é a seguir apresentada: inicialmente, uma carga de sementes de brócolos predefinida foi colocada na parte cônica do leito por onde passa o ar de jorro; esse ar foi aquecido e mantido na temperatura definida para o ensaio; ajustou-se a vazão de trabalho preestabelecida, que permitiu manter as sementes em regime de jorro estável.

O próximo passo foi a atomização da suspensão de recobrimento. A suspensão foi bombeada com vazão constante, por bomba peristáltica, para o bico atomizador de duplo fluido. Na outra entrada do bico atomizador, o ar de atomização foi injetado com pressão também preestabelecida. A suspensão de recobrimento, ao se encontrar com o ar de atomização, na região interna do bico atomizador, foi pulverizada sobre as partículas no interior do leito.

Durante o processo de recobrimento das sementes, foram retiradas amostras em intervalos de tempo de 15 minutos. As amostras foram coletadas por meio de amostrador situado na base cônica do leito de jorro, retirando as sementes próximas da região da fonte, sendo posteriormente utilizadas no cálculo de eficiência do processo. O tempo de recobrimento foi relacionado com a estabilidade do movimento das sementes dentro do leito e dependeu do valor da vazão de suspensão aplicada no recobrimento. Os experimentos de recobrimento das sementes tiveram duração de 90; 105 e 120 minutos.

\section{Materiais empregados}

As sementes de brócolos, Brassica oleracea var. italica e cultivar Ramoso de Brasília, procedentes da Empresa Brasileira de Pesquisa Agropecuária - Hortaliças, lote 501A, apresentaram poder germinativo de $93,71 \%$, pureza de $99,56 \%$ em base úmida, umidade em base úmida de $6,02 \%$ e características físicas correspondentes ao Grupo D de Geldart, classificação conforme a fluidização de sólidos de diversos tamanhos e densidades (GELDART, 1973).

O polímero hidroxietilcelulose QP4400 foi utilizado na formulação da suspensão aquosa polimérica, baseada em ATAIDE (1996), apresentando concentração de 11\% de sólidos. A suspensão foi aplicada sobre as sementes, formando uma película, fornecendo uma superfície de 
recobrimento uniforme e solúvel em água. Os componentes que fizeram parte da suspensão são apresentados na Tabela 1.

TABELA 1. Composição da suspensão de recobrimento. Coating suspension composition.

\begin{tabular}{lc}
\hline Componentes & Concentração em Peso (\%) \\
\hline Hidroxietilcelulose (HEC) & 3,50 \\
PEG 6000 & 0,75 \\
Estearato de magnésio & 1,00 \\
Dióxido de titânio & 2,25 \\
Talco & 3,50 \\
Água & 89,00 \\
\hline
\end{tabular}

\section{Procedimento experimental}

O procedimento experimental consistiu basicamente em colocar 1,0 $\mathrm{kg}$ de sementes de brócolos no leito e ajustar a vazão de ar de jorro, para obter movimento fluidodinâmico característico de jorro estável, para determinada condição de temperatura do ar de jorro. Para o leito em equilíbrio térmico, aplicou-se a suspensão por meio do bico atomizador, mantendo-se a vazão de suspensão e a pressão de ar de atomização. Entre 90 e 120 minutos, encerrou-se a atomização. Nesse momento, finalizou-se o processo, e as sementes foram retiradas do leito.

Um esquema fatorial 23, com quatro pontos centrais, foi aplicado para quantificar e correlacionar as variáveis operacionais com a eficiência do processo ( $\eta$ ) e a germinação das sementes $(\mathrm{G})$. As variáveis operacionais e seus níveis codificados são apresentados na Tabela 2 , estabelecidos em experimentos preliminares.

TABELA 2. Variáveis independentes e seus níveis no planejamento fatorial. Independent variables and respective factorial planning.

\begin{tabular}{lccc}
\hline \multirow{2}{*}{ Fatores } & \multicolumn{3}{c}{ Níveis } \\
\cline { 2 - 4 } & -1 & 0 & 1 \\
\hline Temperatura do ar $-\mathrm{Ta}\left({ }^{\circ} \mathrm{C}\right)$ & 50 & 60 & 70 \\
Vazão de suspensão $-\mathrm{Ws}\left(\mathrm{kg} \mathrm{s}^{-1}\right) \times 10^{4}$ & 1,014 & 1,184 & 1,353 \\
Pressão de atomização $-\mathrm{Pa}(\mathrm{Pa}) \times 10^{-5}$ & 1,034 & 1,379 & 1,724 \\
\hline
\end{tabular}

As análises estatísticas foram realizadas por meio do software Statistica for Windows ${ }^{\circledR}$ (2000). As variáveis utilizadas no planejamento foram codificadas no intervalo -1 a 1 , sendo elas $\mathrm{Z}_{1}, \mathrm{Z}_{2}$ e $\mathrm{Z}_{3}$, obtidas por meio das seguintes relações:

$$
\begin{aligned}
& \mathrm{Z} 1=\frac{\mathrm{Ta}-60}{10} \\
& \mathrm{Z} 2=\frac{\mathrm{Pa}-1,37910^{5}}{0,34510^{5}} \\
& \mathrm{Z} 3=\frac{\mathrm{Ws}-1,18410^{-4}}{0,17410^{-4}}
\end{aligned}
$$

\section{Análise dos dados}

O desempenho do processo foi analisado pela determinação da eficiência do processo, eq.(4), por meio da definição de KMIEC \& KUCHARSKI (1988):

$$
\eta=\frac{\mathrm{M}_{\mathrm{f}}-\mathrm{M}_{0}}{\mathrm{Wsc}_{\mathrm{s}} \mathrm{t}} 100
$$

em que, 
$\eta$ - eficiência, \%;

$\mathrm{M}_{0}$ - massa inicial de partículas, $\mathrm{kg}$;

$\mathrm{M}_{\mathrm{f}}$ - massa final de partículas, $\mathrm{kg}$;

Ws - vazão mássica de suspensão de recobrimento, $\mathrm{kg} \mathrm{s}^{-1}$;

cs - concentração de sólidos na suspensão, $\mathrm{kg} \mathrm{kg}^{-1}$, e

$\mathrm{t}$ - tempo de processo, $\mathrm{s}$.

A fim de identificar variações no poder germinativo das sementes de brócolos recobertas com a suspensão de HEC em leito de jorro, compararam-se os valores obtidos para as análises realizadas antes e após o processo de recobrimento, por meio da elaboração de delineamento inteiramente casualisado (DIC). O delineamento totalizou 13 tratamentos e quatro repetições. Os tratamentos constam das sementes recobertas em 12 ensaios e das sementes não-recobertas, denominadas sementes-testemunha.

Uma amostra de trabalho contendo 200 sementes foi retirada ao acaso, para cada ensaio de semente recoberta e para a semente-testemunha. As sementes foram semeadas em placas de germinação, sobre papel especial embebido em água destilada, com cerca de 2,5 vezes o seu peso. Em cada placa de germinação, foram semeadas 50 sementes. Em seguida, as placas foram tampadas e colocadas em câmara de germinação. As sementes foram mantidas em câmara de germinação por cinco dias, em ambiente de alta umidade relativa, com temperaturas que variaram de 25 a $30^{\circ} \mathrm{C}$ e iluminação permanente. Após esse período, as sementes foram submetidas à avaliação de germinação, sendo contadas apenas as plântulas normais. As sementes que não germinaram retornaram à câmara por mais cinco dias e sofreram nova avaliação. Para uma plântula ser considerada normal, são essenciais: o sistema radicular, eixo apical e cotilédone (BRASIL, 1992).

Para a avaliação da umidificação por saturação de vapor de água, foram utilizadas amostras de $10 \mathrm{~g}$ de sementes de brócolos. As amostras foram colocadas em recipientes herméticos e durante $24 \mathrm{~h}$ foram mantidas em câmara a $25 \pm 1{ }^{\circ} \mathrm{C}$. Os recipientes continham certa quantidade de água e uma peneira interna que mantinha as sementes suspensas, sem o contato direto com a água localizada ao fundo. O teor de água das sementes, dado pela eq.(5), foi medido antes e após 2; 4; 6; 8; 10 e $24 \mathrm{~h}$ de incubação, pelo método da estufa, com circulação forçada de ar, durante $24 \mathrm{~h}$ à temperatura de $105 \pm 2{ }^{\circ} \mathrm{C}$, sendo pesadas novamente até obter peso constante.

$$
\mathrm{U}_{\mathrm{bu}}=\frac{\mathrm{m}_{\mathrm{ag}}}{\mathrm{m}_{\mathrm{ag}}+\mathrm{m}_{\mathrm{s}}} 100
$$

em que,

$\mathrm{U}_{\mathrm{bu}}$ - umidade das sementes em base úmida, \% b.u.;

$\mathrm{m}_{\mathrm{ag}}$ - massa de água contida na semente, $\mathrm{kg}, \mathrm{e}$

$\mathrm{m}_{\mathrm{s}}$ - massa da semente seca, $\mathrm{kg}$.

Realizaram-se três repetições para cada ensaio de recobrimento. Dessa forma,para cada ensaio de recobrimento, foi obtida a curva de umidificação (conteúdo de umidade x tempo) em ambiente saturado de vapor de água (BRASIL, 1992).

\section{RESULTADOS E DISCUSSÃO}

Os resultados de eficiência do processo, obtidos pelo planejamento experimental, são interpretados a partir do cálculo dos efeitos dos fatores isolados (efeitos principais) e dos efeitos de interação entre os fatores. Nota-se que os valores para eficiência do processo estão na faixa de $61,39 \%$ a $80,94 \%$, conforme apresentado na Tabela 3 , sendo os valores para $\eta>65 \%$ considerados adequados, de acordo com trabalhos da literatura para recobrimento de fármacos. 
TABELA 3. Resultados experimentais para eficiência do processo e germinação das sementes de brócolos recobertas em leito de jorro. Experimental results of bed spout coating process efficiency and broccoli seed germination where Ta - stands for air temperature, $\mathrm{Pa}$ - atomization process pressure and Ws - atomization flux.

\begin{tabular}{cccccc}
\hline Ensaios & $\begin{array}{c}\mathrm{Ta} \\
\left({ }^{\circ} \mathrm{C}\right)\end{array}$ & $\begin{array}{c}\mathrm{Pa} \\
(\mathrm{Pa}) 10^{-5}\end{array}$ & $\begin{array}{c}\mathrm{Ws} \\
\left(\mathrm{kgs}^{-1}\right) 10^{4}\end{array}$ & $\begin{array}{c}\eta \\
(\%)\end{array}$ & $\begin{array}{c}\mathrm{G} \\
(\%)\end{array}$ \\
\hline 1 & 50 & 1,034 & 1,014 & 71,76 & 97,0 \\
2 & 70 & 1,034 & 1,014 & 80,94 & 96,0 \\
3 & 50 & 1,724 & 1,014 & 68,25 & 89,5 \\
4 & 70 & 1,724 & 1,014 & 62,06 & 97,0 \\
5 & 50 & 1,034 & 1,353 & 78,60 & 96,5 \\
6 & 70 & 1,034 & 1,353 & 69,64 & 96,0 \\
7 & 50 & 1,724 & 1,353 & 62,75 & 90,5 \\
8 & 70 & 1,724 & 1,353 & 75,51 & 94,0 \\
9 & 60 & 1,379 & 1,184 & 71,56 & 89,5 \\
10 & 60 & 1,379 & 1,184 & 62,43 & 91,0 \\
11 & 60 & 1,379 & 1,184 & 61,39 & 90,5 \\
12 & 60 & 1,379 & 1,184 & 65,82 & 94,0 \\
\hline
\end{tabular}

*Ta - temperatura do ar; Pa - pressão de atomização; Ws - vazão de suspensão.

Por meio do diagrama de Pareto, podem-se visualizar quais parâmetros apresentaram influência significativa no processo, a 90\% de significância (Figura 2). Os valores dos efeitos padronizados revelam que a variável pressão de atomização tem efeito negativo e significativo estatisticamente, e a interação de todas as variáveis independentes $\left(Z_{1} \times Z_{2} \times Z_{3}\right)$ tem efeito positivo e significativo na eficiência do processo.

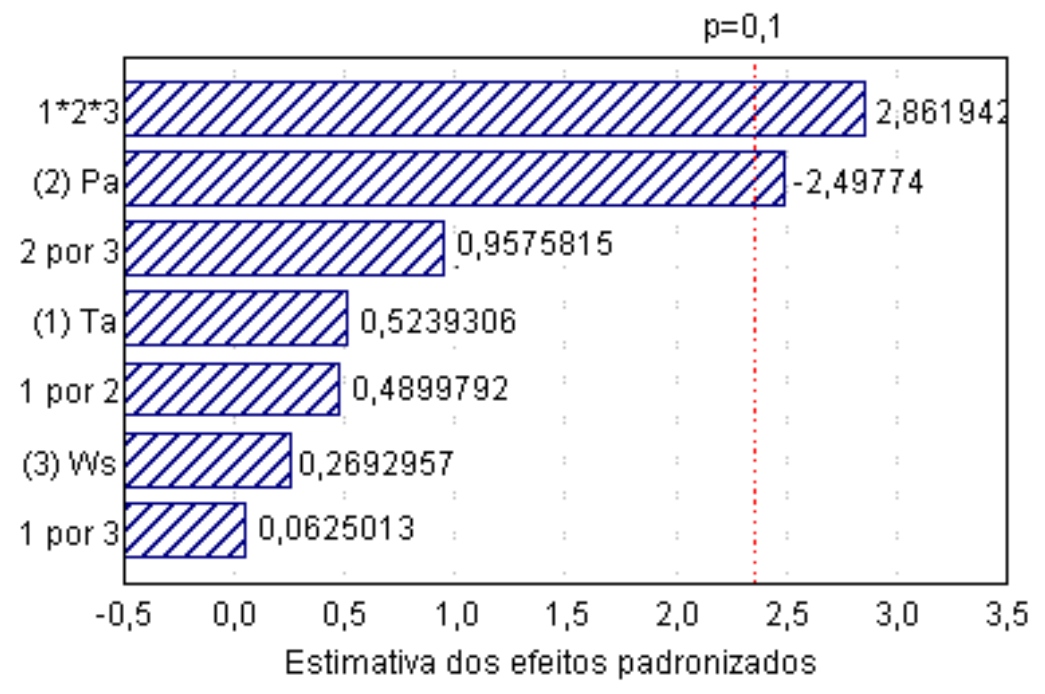

FIGURA 2. Diagrama de Pareto para a eficiência do processo de recobrimento em leito de jorro. Pareto diagram for bed spout process efficiency.

Os ensaios 4 e 7 foram os que apresentaram menor eficiência de processo causada pelo alto valor de pressão de atomização; semelhante observação pode ser feita para os ensaios 3 e 8 com relação à pressão, porém deve ser levada em conta a interação entre as outras variáveis. Em contrapartida, as corridas 2 e 5 apresentaram as melhores eficiências do processo, justificadas pela baixa pressão utilizada e pelo efeito positivo da interação $\left(Z_{1} \times Z_{2} \times Z_{3}\right)$, com níveis (+; -; -) e $(-;-;+)$. Com essa última análise, é possível afirmar que, ao utilizar o nível mais baixo de pressão, juntamente com o maior nível de temperatura e menor nível de vazão ou menor nível de temperatura e maior nível de vazão, têm-se as melhores condições de eficiência do processo. 
Aplicando-se o método da regressão estatística, obteve-se o modelo de primeira ordem para a eficiência do processo em leito de jorro. Embora a eq.(6) seja significativa do ponto de vista do Teste de Fisher $\left(\mathrm{Fcal}=7,28\right.$ para $\mathrm{F}_{2,9}=4,26$ tabelado a 95\%), deve-se restringir sua utilização para a faixa de variação dos fatores avaliados.

$$
\eta=69,22-4,05 Z_{2}+4,64 Z_{1} Z_{2} Z_{3}
$$

$\mathrm{O}$ coeficiente de regressão $\mathrm{R}^{2}$ indica que o modelo consegue explicar $61,82 \%$ da variabilidade de eficiência ocorrida nos ensaios com o valor máximo explicável correspondente a 87,15\%.

Os resultados de viabilidade das sementes recobertas, obtidos do planejamento experimental, foram interpretados a partir do cálculo dos efeitos principais e dos efeitos de interação entre os fatores. Os valores do poder germinativo das sementes, que passaram pelo recobrimento com a suspensão de hidroxietilcelulose, variam de 89,5 a 97\%, conforme resultados apresentados na Tabela 4. Esses resultados são considerados adequados e estão de acordo com os obtidos para sementes de brócolos (MELLO et al., 1999).

TABELA 4. Resultados de germinação para sementes recobertas e não-recobertas. Germination results for coated and non-coated seeds.

\begin{tabular}{ccccc}
\hline Tratamentos & Germinação & $\begin{array}{c}\text { Variação Máxima entre } \\
\text { as Repetições (\%) }\end{array}$ & $\begin{array}{c}\text { Variação Máxima (\%) } \\
(\text { ISTA, 1985) }\end{array}$ & $\begin{array}{c}\text { Tukey } \\
95 \%\end{array}$ \\
\hline 1 & 97,0 & 6 & 7 & $\mathrm{a}$ \\
2 & 96,0 & 6 & 8 & $\mathrm{a}$ \\
3 & 89,5 & 6 & 12 & $\mathrm{a}$ \\
4 & 97,0 & 6 & 7 & $\mathrm{a}$ \\
5 & 96,5 & 6 & 8 & $\mathrm{a}$ \\
6 & 96,0 & 4 & 8 & $\mathrm{a}$ \\
7 & 90,5 & 8 & 12 & $\mathrm{a}$ \\
8 & 94,0 & 6 & 10 & $\mathrm{a}$ \\
9 & 89,5 & 12 & 11 & $\mathrm{a}$ \\
10 & 91,0 & 11 & 12 & $\mathrm{a}$ \\
11 & 90,5 & 2 & 10 & $\mathrm{a}$ \\
12 & 94,0 & 6 & 9 & $\mathrm{a}$ \\
Testemunha & 95,5 & 6 & & $\mathrm{a}$ \\
\hline
\end{tabular}

O diagrama de Pareto, na Figura 3, permite identificar o efeito negativo da pressão de atomização na germinação das sementes recobertas, com $95 \%$ de confiabilidade estatística. Os valores do efeito padronizado revelam que apenas a variável pressão de atomização tem efeito significativo estatisticamente, e é negativo.

A resposta negativa nos valores de germinação das sementes, ocorrida ao se utilizar pressão de atomização em nível maior $(+1)$, pode ser atribuída aos choques mecânicos. Esse fato foi verificado durante a fase experimental, para pressão de atomização de $1,72410^{5} \mathrm{~Pa}$, ocorrendo fortes impactos das sementes com as paredes do leito.

Entretanto, a temperatura do ar de jorro $\left(\mathrm{Z}_{1}: \mathrm{Ta}\right)$ não causou efeito para a germinação das sementes, como se poderia esperar. Como a atomização da suspensão foi contínua durante o processo de recobrimento, pode-se considerar que as sementes estavam constantemente envolvidas por uma película úmida, e essa umidade superficial fez com que a temperatura das sementes se mantivesse aproximadamente igual à temperatura de bulbo úmido do ar, bastante inferior à temperatura de entrada do ar no leito.

A finalidade do DIC foi determinar possíveis diferenças entre o potencial médio de germinação das sementes recobertas e não-recobertas. 


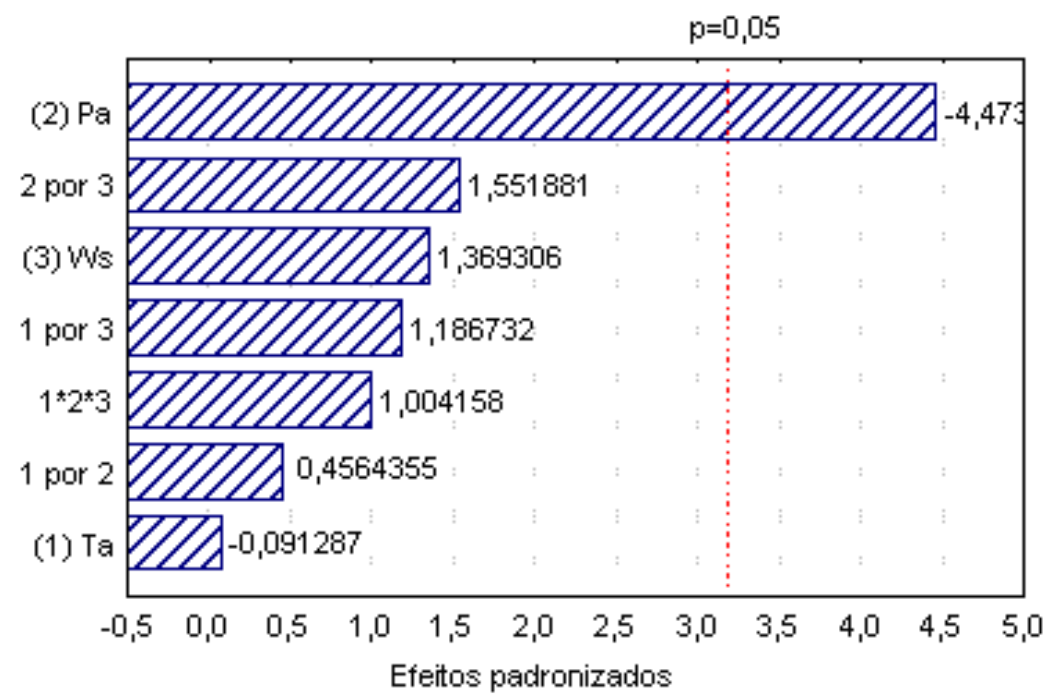

FIGURA 3. Diagrama de Pareto para a germinação das sementes, após o processo de recobrimento em leito de jorro. Pareto diagram for seed germination after bed spout processing.

A análise estatística realizada com os resultados da Tabela 4 revela que o processo de recobrimento em leito de jorro não alterou a viabilidade das sementes em nenhum ensaio, indicando que não houve prejuízo às estruturas essenciais do embrião e às partes que o constituem e o envolvem. WEST et al. (1985) verificaram que a aplicação da cobertura à base de cloreto de polivinilideno (PVDC), em sementes de soja, promoveu germinação mais rápida do que nas sementes sem a cobertura.

A interpretação dos resultados de umidificação das sementes recobertas foi realizada utilizando-se da curva obtida de umidade em base úmida das sementes, em função do tempo de exposição ao ambiente de vapor saturado (curva de umidificação), para as sementes tratadas em cada um dos ensaios de recobrimento (Figura 4). MENDONÇA et al. (2003), analisando a umidificação das sementes de brócolos, verificaram que a absorção foi maior e mais rápida nas primeiras 12 horas, em atmosfera úmida.

As curvas de umidificação referentes aos ensaios 2; 4 e 6 foram ilustradas na mesma Figura 4, em razão de terem apresentado, ao final do ensaio de recobrimento, umidade inferior a 7,3\%, que também era a umidade inicial das sementes-testemunha.

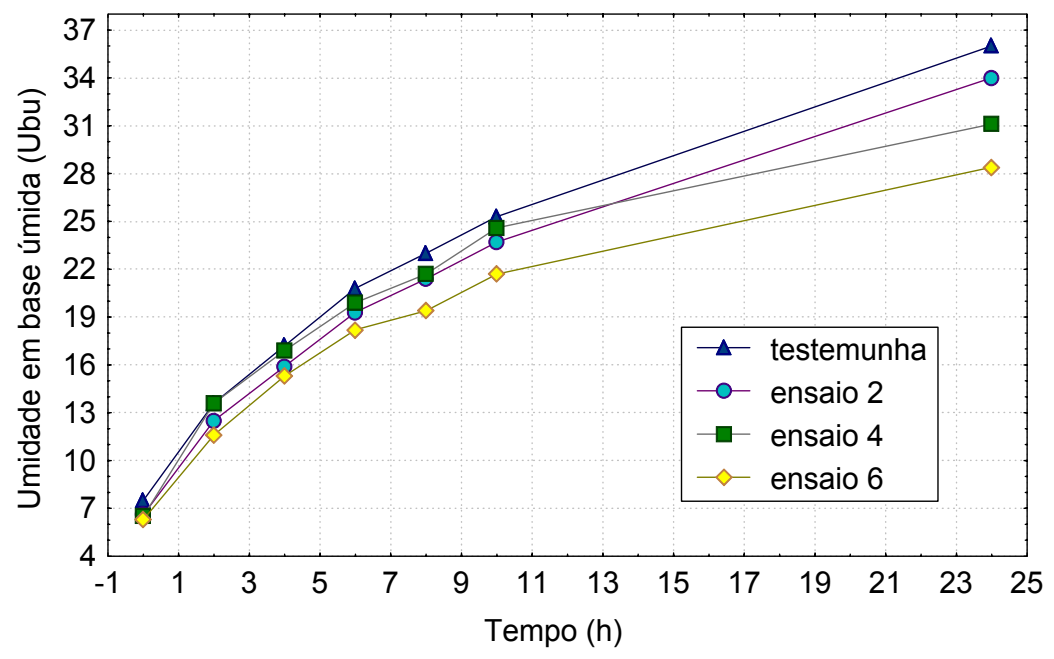

FIGURA 4. Curvas de umidificação das sementes recobertas em leito de jorro dos ensaios 2; 4; 6 e testemunha. Spouted bed coated seeds humidification curves for trials number 2; 4; 6 and non-coated. 
As sementes recobertas nesses ensaios chegaram ao final das 25 horas de análise apresentando umidade em base úmida na faixa de 28 a 34\%. Entretanto, a umidade das sementes-testemunha manteve-se sempre acima dos valores das sementes recobertas e atingiram, no período de $24 \mathrm{~h}, 36 \%$ de umidade em base úmida. Comparando-se os resultados aos de MENDONÇA et al. (2003), para o mesmo tipo de teste, verificou-se que as sementes de brócolos atingiram os teores de umidade em menor tempo de análise, diferença que pode ter ocorrido pelas diferentes condições de temperatura e saturação de vapor de água utilizadas nos testes.

As curvas de umidificação ilustradas na Figura 5 (ensaios de recobrimento $1 ; 3 ; 5 ; 7$ e 8 ) apresentaram umidade inicial superior a 7,3\%, valor que corresponde à umidade inicial das sementes-testemunha.

As sementes recobertas nos ensaios $1 ; 3 ; 5 ; 7$ e 8 chegaram ao final da análise com umidade em base úmida na faixa de 26 a 34\%. Entretanto, as sementes-testemunha sofreram acréscimo de umidade superior, durante as $24 \mathrm{~h}$ de análise, ultrapassando os valores de umidade das sementes recobertas em todos os ensaios após exposição ao ambiente saturado por 4,5 horas ou mais.

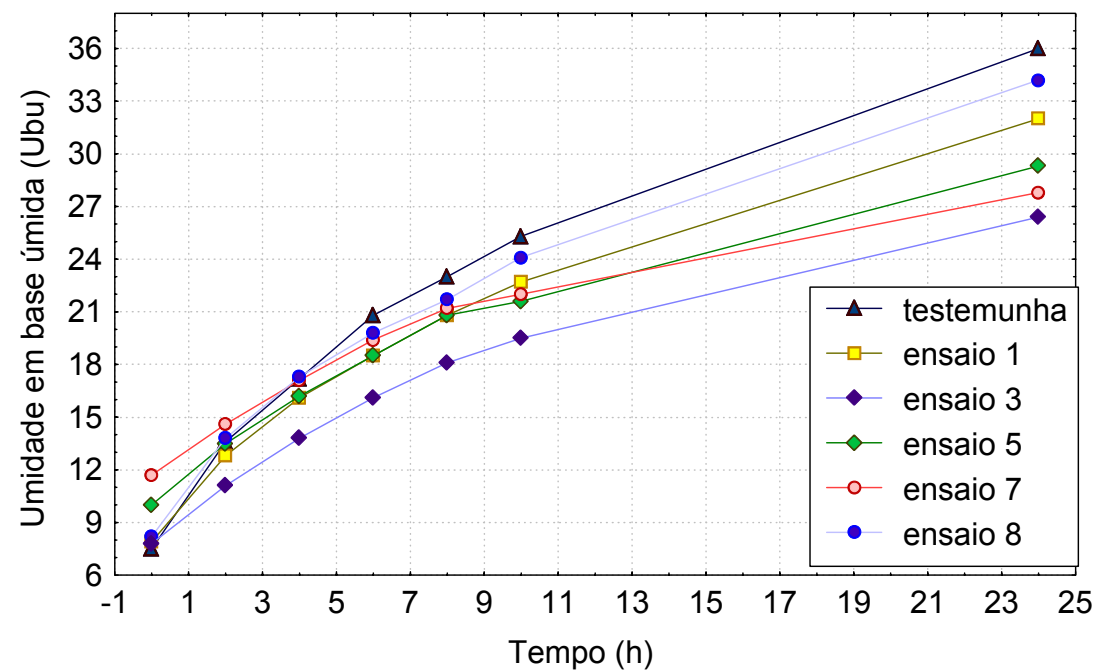

FIGURA 5. Curvas de umidificação das sementes recobertas em leito de jorro dos ensaios 1; 3; 5; 7; 8 e testemunha. Spouted bed coated seeds humidification curves for trials number $1 ; 3 ; 5 ; 7 ; 8$ and non-coated.

Constatou-se inclinação inferior das curvas nos ensaios 5 e 7, os quais apresentam a variável independente vazão de suspensão em nível superior e temperatura do ar de jorro em menor nível, de valor $8 \mathrm{~mL} \mathrm{~min}^{-1}$ e $50{ }^{\circ} \mathrm{C}$, respectivamente.

\section{CONCLUSÕES}

A eficiência do processo de recobrimento de sementes de brócolos em leito de jorro foi influenciada positivamente pela menor pressão de atomização e pela interação positiva das três variáveis independentes: temperatura do ar de jorro, pressão do ar de atomização e vazão de suspensão de recobrimento.

As melhores eficiências do recobrimento em leito de jorro foram obtidas com o menor nível de pressão de atomização (1,034 $10^{5} \mathrm{~Pa}$ ) (15 psig), juntamente com o maior nível de vazão de suspensão $\left(8 \mathrm{~mL} \mathrm{~min}^{-1}\right)$ e o menor nível de temperatura do ar de jorro $\left(50^{\circ} \mathrm{C}\right)$; ou o menor nível de

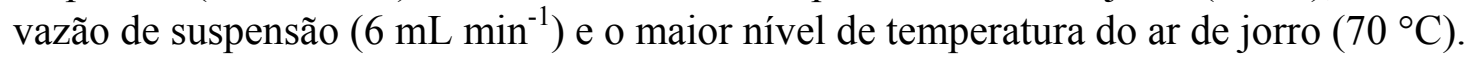

O poder de germinação das sementes recobertas em leito de jorro foi influenciado negativamente pela pressão de atomização. 
A hidroxietilcelulose proporcionou discreto comportamento protetor para as sementes recobertas e expostas a condições de alta concentração de vapor de água ambiente e não prejudicou a absorção de água livre para a germinação.

\section{REFERÊNCIAS}

ATAIDE, C.H. Estudo do recobrimento de comprimidos em leito de jorro e jorro fluidizado. $188 \mathrm{f}$. Tese (Doutorado em Engenharia Química) - Faculdade de Engenharia Química, Universidade Estadual de Campinas, Campinas, 1996.

BRASIL. Ministério da Agricultura. Regras de análise de sementes. Brasília: SND/CLAV, 1992. $365 \mathrm{p}$.

GELDART, D. Gas fluidization technology. New York: John Wiley, 1973. 476 p.

ISTA - INTERNATIONAL SEED TESTING ASSOCIATION International rules for seed testing, Seed Science and Technology, Switzerland, v.13, p.322-6, 1985.

KMIEC, A.; KURCHARSKI, J. The effect of process parameters on mass distributions and the efficiency of tablet coating in a spouted bed. In: INTERNATIONAL DRYING SYMPOSIUM, 6., 1988, Versailles. Proceedings ... Nancy: ENSIC-INPL, 1988.

LIU, L.X.; LITSTER, J.D. The effect of particle shape on the spouting properties of non spherical particles. Powder Technology, Warwick, v.66, p.59-67, 1991.

LOPES FILHO, F.; ASSUNÇÃO, M.V.; VIEIRA, F.V. Efeito da embalagem, período e local de armazenamento na qualidade de sementes de sorgo. Pesquisa Agropecuária Brasileira, Brasília, v.21, n.1, p.802-11, 1986.

LYNE, C.W.; JOHNSTON, H.G. The selection of pelletisers. Powder Technology, Warwick, v.29, n.1, p.211-16, 1981.

MELLO, S.C.; SPINOLA, M.C.M.; MINANI, K. Método de avaliação da qualidade fisiológica de sementes de brócolos. Scientia Agrícola, Piracicaba, v.56 n.4, 1999. Suplemento

MENDONÇA, E.A.F.; RAMOS, N.P.; FESSEL S.A. Adequação da metodologia do teste de deterioração controlada para sementes de brócolos (Brassica oleracea L. - var. Itálica). Revista Brasileira de Sementes, Jaboticabal, v.25, n.1, p.18-24, 2003.

SAMPAIO, T.G.; SAMPAIO, N.V. Recobrimento de sementes. Informativo ABRATES, Londrina, v.4, n.3, p.20-51, 1994.

STATISTICA for Windows ${ }^{\circledR}$ " $95 / 98 / 2000 / N T$. StatSoft. Version 55, serie: 0300-A-N4, (19842000).

TAYLOR, A.G.; HARMAN, G.E. Concepts and technologies of selected seed treatments. Phytopathology, St. Paul, v.28, n.1, p.321-39, 1990.

VALDES, V.M.; BRADFORD, K.J. Effects of seed coating and osmotic priming on the germination of lettuce seeds. Journal of the American Society for Horticultural Science, Alexandria, v.112, n.1, p.153-6, 1987.

WEST, S.H.; LOFTIN, S.K.; WAHL, M.; BATICH, C.D.; BEATTY, C.L. Polymers as moisture barriers to maintain seed quality. Crop Science, Madison v.25, n.1, p.941-4, 1985. 